\title{
CDISC SDTM Multiple Sclerosis Findings About Test Code Terminology
}

National Cancer Institute

\section{Source}

National Cancer Institute. CDISC SDTM Multiple Sclerosis Findings About Test Code

Terminology. NCl Thesaurus. Code C117741.

Terminology associated with the multiple sclerosis findings about test codes codelist of the Clinical Data Interchange Standards Consortium (CDISC) Study Data Tabulation Model (SDTM). 